\title{
Contextual Factors Influencing Cost and Quality Decisions in Health and Care: A Structured Evidence Review and Narrative Synthesis
}

\author{
Iestyn Williams ${ }^{1}$, Hilary Brown ${ }^{1}$, Paul Healy ${ }^{2}$
}

\begin{abstract}
Background: Decisions affecting cost and quality are taken across health and care but investigation of the mediating role of context in these is in its infancy. This paper presents a synthesis of the evidence on the contextual factors that influence 'decisions of value' - defined as those characterised by having a significant and demonstrable impact on both quality and resources - in health and care. The review considers the full range of resource/quality decisions and synthesises knowledge on the contextual drivers of these.

Methods: The method involved structured evidence review and narrative synthesis. Literature was identified through searches of electronic databases (HMIC, Medline, Embase, CINAHL, NHS Evidence, Cochrane, Web of Knowledge, ABI Inform/Proquest), journal and bibliography hand-searching and snowball searching using citation analysis. Structured data extraction was performed drawing out descriptive information and content against review aims and questions. Data synthesis followed a thematic approach in accordance with the varied nature of the retrieved literature.

Results: Twenty-one literature items reporting 14 research studies and seven literature reviews met the inclusion criteria. The review shows that in health and care contexts, research into decisions of value in health and care is in its infancy and contains wide variation in approach and remit. The evidence is drawn from a range of service and country settings and this reduces generalisability or transferability of findings. An area of relative strength in the published evidence is inquiry into factors influencing coverage and commissioning decisions in health care systems. Allocative decisions have therefore been more consistently researched than technical decisions. We use Pettigrew's (1985) distinction between inner and outer context to structure analysis of the range of factors reported as being influential. These include: evidence/ information, organisational culture and governance regimes, and; economic and political conditions.

Conclusion: Decisions of value in health and care are subject to range of intersecting influences that often lead to a departure from narrow notions of rational decision-making. Future research should pay greater attention to the relatively under-explored area of technical, as opposed to allocative, decision-making.

Keywords: Healthcare Decision-Making, Cost, Quality, Literature Review, Health Management

Copyright: (c) 2018 The Author(s); Published by Kerman University of Medical Sciences. This is an open-access article distributed under the terms of the Creative Commons Attribution License (http://creativecommons.org/licenses/ by/4.0), which permits unrestricted use, distribution, and reproduction in any medium, provided the original work is properly cited.

Citation: Williams I, Brown H, Healy P. Contextual factors influencing cost and quality decisions in health and care: a structured evidence review and narrative synthesis. Int J Health Policy Manag. 2018;7(8):683695. doi:10.15171/ijhpm.2018.09
\end{abstract}

\section{Article History:}

Received: 4 May 2017

Accepted: 24 January 2018

ePublished: 28 February 2018

\section{Introduction}

Many governments now find themselves faced with unprecedented constraints on their health and care spending capacity whilst demands and expectations continue to increase. This has led to the championing of investment and disinvestment decision-making that incorporates opportunity cost and budget impact, alongside quality and outcomes. ${ }^{1}$ The development and spread of formal coverage decisionmaking bodies internationally has prompted inquiry into the drivers of resource allocation decisions of this kind. However, significant investment decisions are also made in other areas: for example service redesign, and changes to workforce and governance arrangements. Although considerations of both benefit and resource impact arguably should infuse such policy and programme decision-making, this implies a level of rationality on the part of decision-makers which may not always be present, possible or even desirable in practice. Whilst the psychology of decision-making has been subject to much study and theorisation, such decisions are also likely to be influenced by aspects of context. This paper presents findings from an evidence synthesis carried out in order to understand the contextual factors that are influential in these decision-making domains, and which therefore facilitate or attenuate the pursuit of quality and affordability. The focus is on 'decisions of value' - defined as being characterised by a significant and demonstrable impact on both quality and resources. The paper begins with a definition of terms and an explanation of the scope and conceptual foundation of the review. This is followed by a description of the study objectives, methods and a comparative thematic analysis of findings. Pettigrew's ${ }^{2}$ distinction between inner and outer context is used to structure analysis of the factors identified, 
and the interplay between them as influencers of decisionmaking. Results of the analysis are presented and discussed alongside recommendations for future theoretical and empirical enquiry, as well as for decision-making in practice.

\section{Decisions of Value in Health and Care}

The term 'decisions of value' is used here to refer to decisions with substantial and direct implications for both cost/finance and quality/outcomes in health and care settings. ${ }^{3}$ Across health care systems there are powerful pressures on local decisionmakers to improve outcomes whilst reducing expenditure. ${ }^{4}$ However, achieving these twin aims can be impeded by, for example, organisational siloes, ${ }^{5}$ and clinical-managerial division. ${ }^{6}$ In this study, we examine formal decision-making processes undertaken by, for example: governing bodies within health and care organisations; local government departments; healthcare insurance agencies; service planners, hospital senior management and so on. The focus on formal decision bodies means that continuous and/or covert decisionmaking, whilst important, is beyond our remit. ${ }^{7}$ Similarly, our focus is specifically on meso level decision-making tiers which include those at the organisational or inter-organisational level. Although the characteristics of such decision-making contexts will vary from country to country, in each case they are distinct from macro (eg, national/governmental) or micro (eg, clinical/practice) levels, each of which warrant separate study in their own right. These other decision-making tiers are therefore only included here to the extent that they, in themselves, constitute contextual factors influencing mesolevel decision-making.

We take 'decision-making' to mean the act of selecting a course of action from among alternatives (including 'do nothing'). Our focus is therefore on option selection rather than other decision features such as agenda setting, implementation and review. ${ }^{8}$ It is this aspect of decisionmaking for which the imperative to draw on best evidence to maximise outcomes is most often invoked. ${ }^{9}$ The logic of this rationality can be allocative (ie, relating to distribution of resources between alternative interventions or programmes) or technical (ie, relating to investments made in order to enhance organisational capacity and functioning). In this context we might consider allocative decisions to include for example: selecting treatments for inclusion in insurance packages or formularies, and purchasing or contracting for specific health and care services. Technical decisions might include: organisational mergers and takeovers; investment in programmes of service improvement or engagement; major workforce reorganisation; adoption of new technologies, organisational systems, and so on. This distinction is important as it is rare for the full range of decisions to be included in studies of decision-making (as we demonstrate in this paper) (Box 1).

There is a rich and longstanding theoretical literature which considers the rationality of decision-making and attendant requirements of perfect knowledge and predictability of decision outcomes. ${ }^{10,11}$ In particular, theories have centred on psychology and the mediating role played by cognitive biases and group dynamics such as consensus building and argumentation, as well as the influence of expertise and seniority. ${ }^{12-14}$ Characteristics of decisions and those charged with making them vary and have been found to be important in shaping decision outcomes. ${ }^{15-17}$ These characteristics include the complexity of the decision and extent of decision precedent, which influence both speed of decision-making and level of supporting information typically accessed in the decision-making process. Decision-maker characteristics such as professional role and values, personality, cognitive style and demographic factors such as age, length of tenure and education have been found to influence aspects of decision-making such as levels of risk-taking, volume and type of information sought. ${ }^{18,19}$

By comparison, investigation of the mediating role of context in decision-making is under-developed. Dobrow et $\mathrm{al}^{15}$ note that a 'normative evidence-based' mind-set is often somewhat at odds with a 'practical-operational' orientation, in which contextual factors are acknowledged as attenuating the strict application of best evidence. Contextual factors are to some extent accounted for in institutional approaches. These schools also question the explanatory power of instrumentalist models of decision-making, instead emphasizing the institutional outcomes of legitimacy and recognition, and counter logics of organisational isomorphism. ${ }^{20}$ In order to disaggregate the relevant features of this institutional context it is helpful to draw on Pettigrew's ${ }^{2}$ broad distinction between inner and outer context:

"Inner context refers to factors from within the organization

Box 1. Examples of Decisions of Value in Health and Care
Allocative:
A local government agency commissions a service from the charity/third sector.
A health or care provider decides to invest in a new treatment, device or equipment.
A prescribing group decides to replace a treatment and thereby remove it from a formulary list.
Technical:
Two health and/or social care organisations decide to partially or fully merge, forming a new organisation.
A service planning body decides to downgrade or close an in-house service or organisation.
A provider organisation decides to undertake substantive internal audit, governance and/or review of its operations.
A provider organisation decides to adopt a set of new managerial structures and/or arrangements.
A provider organisation decides to invest in a major update of its physical or technological infrastructure.
A provider organisation decides to significantly increase or decrease its workforce levels.
A service planning body or provider organisation decides to lead a programme of funded service improvement.
A service planning body or provider organisation decides to invest in a programme of patient/public/stakeholder engagement. 
eg, structure, culture, power and political characteristics; and outer, to factors external to the organization such as industry sector, economic, political and social context. This is a handy simplification, although may not be so easy to identify in practice, as these boundaries are sometimes permeable." 1

Frameworks such as that of Bate et $\mathrm{al}^{22}$ add to the category of inner context factors such as size, scale and complexity of the organisational unit; degree of organisational stability, and; prior financial and service performance. To the outer context they add factors such as: regulatory environment and market forces. However, settling on a definitive and granular categorisation is problematic given that, as Squires et $\mathrm{al}^{23}$ note 'no one framework is sufficiently inclusive or comprehensive about what comprises context.' What's more, such frameworks have typically been designed to analyse change processes and it is not clear that the extent to which any explanatory power in this domain is transferable to the analysis of decisionmaking.

In this review we have grouped factors under descriptive headings selected to enable capture of all contextual factors reported in the included studies (see Box 2).

Although we might assume that 'dynamic decision-making'? is the product of the interaction between such factors and human dimensions, the nature of these factors and this interaction with formal decision functions is not well understood in health and care settings.

In summary then, decisions of value are understood to be non-routine decisions that impact substantially and explicitly on both costs and outcomes, and which require consideration of options. The aims of this evidence synthesis are to understand the contextual factors that influence decisions of value in health and care, and to draw conclusions and identify areas for future enquiry. The specific objective is to identify and synthesise previous empirical studies of the relationship between contextual (inner and outer) factors and decisions of value.

\section{Box 2. Categories of Factors}

Sources of information: refers to factors reported in the literature such as formal evidence and tacit information.

Interests: refers to the range of stakeholders that may seek to influence decisions, including professional, commercial, patients and so on. 'Interests' can be located predominantly in either the inner or outer context.

Organisational characteristics: covers factors such as size, structure and resource levels of the organisation in which the decision-making function is embedded.

Governance and leadership: refers to the modes of practice in relation to leading and managing the organisations within which the decision-making function is embedded.

Geography: covers factors such as extent of rurality and accessibility for patient populations.

Economics: refers to extent of available resources, and system payment mechanisms.

Relationship to government: refers to factors deriving specifically from political overseers and their agents, including regulation, contracts, services frameworks and standards.

\section{Materials and Methods}

The method employed for this study is structured evidence review and narrative synthesis. Following initial scoping searches of online search engines (Google Scholar and NHS Evidence) a list of search terms and inclusion criteria were developed. Full searches were then carried out of health and social care databases keywords and abstracts (HMIC, Medline, Embase, CINAHL, NHS Evidence, Cochrane) and selected non-health databases (Web of Knowledge and ABI Inform/Proquest). Follow-up searches focussing on journals and mesh terms identified as most relevant from these initial searches were conducted along with hand-searching of identified bibliographies and reference lists. Snowball searching using citation analysis and bibliography scanning was then performed with a final google scholar search carried out in February 2015 (Box 3).

Included documents were empirical (either new research or evidence synthesis) and published between January 1990 and February 2015 in academic peer reviewed formats. The review was international in scope but confined to English language reporting. Included items relate to formal and explicit decisions where options/alternatives are available (eg, 'next best course of action' or 'do nothing') with demonstrable implications for quality and finance, and which considered the influence of a contextual factor or factors on these, in a health and/or care context (Figure).

For all included items, structured data extraction was performed drawing out descriptive information and content against the review aims and questions (see Table 1). Data synthesis was conducted in accordance with the nature of the evidence base and a narrative, thematic approach was adopted as the best approach for combining studies employing divergent methods. ${ }^{24}$ Comparisons were made across studies in order to provide an overview of the main themes and characteristics of the evidence base against research aims and questions. ${ }^{25}$ A key aim was to identify factors reported as influencing decisions of value. A coding framework was developed from a combination of the self-reported categories employed in studies and additional categorisation work of the authors (see Table 2). This was applied and developed iteratively until each reported factor was assigned a code.

The interdisciplinary nature of the evidence base and the challenges of applying quality criteria across research

Box 3. Example Search

Search strategy: influences on cost/quality decision-making in health

\section{Databases: CINAHL}

Search terms: 'Decision making' or 'Investment' or 'Management' or 'Governance' or 'Adoption' or 'Choice' or 'Selection' or 'Strategy' or 'Planning' or 'Quality' or 'Service improvement' or 'Improvement' or 'Innovation' or 'Cutbacks' or 'Rationing' And 'Causes' or 'Drivers' or 'Influences' or 'Factors' or 'Finance' or 'Cost' or 'Cost effectiveness' or 'Evidence' or 'Context' 


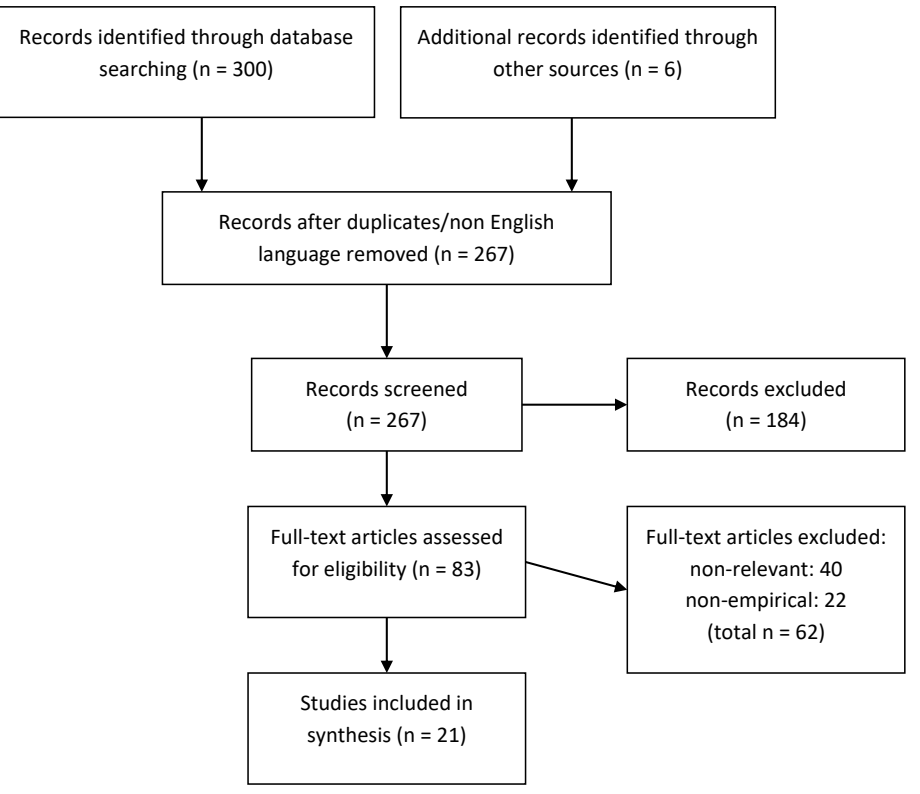

Figure. PRISMA Flowchart.

paradigms meant that assessment of each included item was confined to considerations of relevance rather than research quality (see Table 1). However, by excluding non-peerreviewed literature we ensured only studies with explicit methods and which followed a defined research designs were included. Where previous evidence syntheses of subsections of the literature were identified which meet the inclusion criteria, we incorporated the prior synthesis to our own instead of disaggregating and re-analysing each of the relevant studies contained within them. For example, Eddama and Coast ${ }^{26}$ and Williams et $\mathrm{al}^{27}$ both review the literature on the influence of economic information in allocative decisionmaking and we have reviewed and incorporated their analysis and conclusions.

\section{Results}

Twenty-one literature items reporting 14 research studies and seven literature reviews met the inclusion criteria. Six of the research studies were carried out in the US with three from each of the United Kingdom and Canada and the remaining two from countries in Europe and Asia. Of the empirical items included, eight reported from research into allocative decision-making, five reported on research into technical decision-making and six of these covered both. Four reviews covered allocative decision-making and two covered both allocative and technical decisions. Details of the included studies are presented in Table 1 and a breakdown of the factors reported in each included literature item are presented in Table 2.

\section{Strengths and Limitations of the Evidence}

The review shows that in health and care contexts, research into decisions of value is in its infancy and contains wide variation in approach and remit. For example some studies seek to identify inductively the full range of influencing factors whereas others measure correlations between a narrower range of pre-identified factors and a dependent variable. This prevents us from aggregating the reported influence of factors across studies. Combined with the lack of replication or critical appraisal of studies - especially in relation to technical decision-making - this makes it premature to issue definitive statements regarding the relative influence of factors.

As well as this, the evidence is drawn from a range of service and country settings - albeit our searches identified few studies from lower and middle-income countries - and this reduces generalisability or transferability of findings. Furthermore, the variety of definitions for phenomena such as 'leadership, 'culture' and 'resources', means that assessment of their power as influencers is subject to uncertainty. These variations reflect differences of research tradition. For example although the literature is dominated by health services research it contains contributions from management studies, operations research and political science, and draws from both qualitative and quantitative research paradigms. More work is therefore required to develop a taxonomy of factors that can be clearly defined, measured and analysed in different settings and to help facilitate reconciliation of insights from these divergent schools.

An area of relative strength in the published evidence is enquiry into the factors influencing coverage and commissioning decisions in healthcare systems. ${ }^{27-30}$ The factors influencing these allocative decisions have therefore been more consistently explored than factors affecting technical decision. The greater variety in technical decisionmaking makes it difficult to draw definitive conclusions regarding the influence of contextual factors. These caveats notwithstanding, the following sections describe inner and outer contextual factors and their influence as reported in the literature.

\section{Inner Context}

Factors deriving from the inner context reported as influential 


\section{Table 1. Included Literature}

\begin{tabular}{|c|c|c|c|c|}
\hline Source & Decisions & Methods & Relevant Research Aims/Question & Relevance to Review \\
\hline Abelson $^{31}$ & $\begin{array}{l}\text { Community decision-making } \\
\text { processes in Canada }\end{array}$ & $\begin{array}{l}\text { Case studies involving interviews, secondary sources and } \\
\text { observation }\end{array}$ & $\begin{array}{l}\text { Explores the role that context plays in shaping community } \\
\text { decision-making processes }\end{array}$ & Covers allocative and technical decisions \\
\hline Bazzoli et a $\left.\right|^{32}$ & $\begin{array}{l}\text { Investment in plant and equipment in } \\
\text { US hospitals }\end{array}$ & $\begin{array}{l}\text { Quantitative analysis of routine data: on hospital } \\
\text { finances, performance etc }\end{array}$ & $\begin{array}{l}\text { To examine effects of financial pressure on hospital operations } \\
\text { including investments in plant and equipment }\end{array}$ & $\begin{array}{l}\text { Covers technical decision-making in a } \\
\text { specific system setting }\end{array}$ \\
\hline Castro et al ${ }^{13}$ & $\begin{array}{l}\text { Decisions over the adoption/diffusion } \\
\text { of new innovations in Italy }\end{array}$ & $\begin{array}{l}\text { Analysis of routine data, using regression analysis, on } \\
\text { expensive medical equipment (eg, MRI), comparing } \\
\text { public and private hospitals }\end{array}$ & $\begin{array}{l}\text { To investigate the relationship between reimbursement systems } \\
\text { and decisions to adopt technological medical innovations }\end{array}$ & $\begin{array}{l}\text { Covers technical decision-making in a } \\
\text { specific system setting }\end{array}$ \\
\hline Denis et a $\left.\right|^{34}$ & $\begin{array}{l}\text { Merger decisions in healthcare in } \\
\text { Quebec, Canada }\end{array}$ & $\begin{array}{l}\text { Longitudinal case study using documentary analysis and } \\
\text { interviews }\end{array}$ & $\begin{array}{l}\text { To analyse the determinants of a merger between two publicly } \\
\text { funded hospitals }\end{array}$ & $\begin{array}{l}\text { Covers technical decisions in a specific } \\
\text { system setting }\end{array}$ \\
\hline Dranove et $\mathrm{al}^{35}$ & $\begin{array}{l}\text { HMO formulary inclusion decisions, } \\
\text { US }\end{array}$ & $\begin{array}{l}\text { Survey of } \mathrm{HMO} \text { directors of pharmacy analysed using } \\
\text { logistical regression analysis }\end{array}$ & $\begin{array}{l}\text { To identify economic and organisational factors that affect } \\
\text { likelihood of inclusion of new drugs }\end{array}$ & $\begin{array}{l}\text { Covers allocative decision-making in a } \\
\text { US setting }\end{array}$ \\
\hline Eddama and Coast ${ }^{26}$ & $\begin{array}{l}\text { Review and synthesis of the } \\
\text { international literature on use of } \\
\text { economic evidence in decisions to } \\
\text { invest in healthcare interventions }\end{array}$ & Literature review & $\begin{array}{l}\text { To investigates the role of economic evidence in healthcare } \\
\text { coverage decision-making }\end{array}$ & $\begin{array}{l}\text { Reviews allocative decisions on } \\
\text { technology coverage across a range of } \\
\text { settings }\end{array}$ \\
\hline Fischer $^{36}$ & $\begin{array}{l}\text { Review and synthesis of the } \\
\text { international literature on allocative } \\
\text { decision-making at the pan- } \\
\text { organisational level }\end{array}$ & Literature review and documentary analysis & $\begin{array}{l}\text { To summarise factors that influence decision outcomes and } \\
\text { appraisal criteria as measured in quantitative studies }\end{array}$ & $\begin{array}{l}\text { Reviews allocative decisions on } \\
\text { technology coverage across a range of } \\
\text { settings, excludes qualitative studies }\end{array}$ \\
\hline $\begin{array}{l}\text { Fraser and } \\
\text { Estabrooks }^{28}\end{array}$ & $\begin{array}{l}\text { Review and synthesis of the } \\
\text { international literature on home care } \\
\text { decision-making }\end{array}$ & Literature review & $\begin{array}{l}\text { To understand what factors influence case managers' resource } \\
\text { allocation decisions in home care }\end{array}$ & $\begin{array}{l}\text { Synthesises literature on allocative } \\
\text { decision although relatively little } \\
\text { research identified }\end{array}$ \\
\hline Fraser et al ${ }^{37}$ & $\begin{array}{l}\text { Case management resource allocation } \\
\text { decisions in Canada }\end{array}$ & $\begin{array}{l}\text { Ethnographic study of a home care programme using } \\
\text { interviews, card sorts and participant observation }\end{array}$ & $\begin{array}{l}\text { To explore factors that influence case managers' resource } \\
\text { allocation decisions in pediatric home care }\end{array}$ & $\begin{array}{l}\text { Covers allocative decisions in a specific } \\
\text { system setting }\end{array}$ \\
\hline Hensher and Fulop ${ }^{38}$ & Health authorities in London, UK & Survey and interviews & $\begin{array}{l}\text { To assess the influence needs assessment has had on decision- } \\
\text { making }\end{array}$ & $\begin{array}{l}\text { Covers allocative and technical decision- } \\
\text { making in a specific system setting }\end{array}$ \\
\hline Kisa et a ${ }^{39}$ & $\begin{array}{l}\text { Financial decision-makers at } \\
\text { organisational level in hospitals } \\
\text { (public and private) in Ankara, Turkey }\end{array}$ & $\begin{array}{l}\text { Survey of people in charge of financial decisions in } 14 \\
\text { private hospitals and } 66 \text { outpatient clinics and imaging } \\
\text { centres }\end{array}$ & $\begin{array}{l}\text { To investigate how involved finance officers are in decision- } \\
\text { making in healthcare organisations }\end{array}$ & $\begin{array}{l}\text { Covers technical decision-making in a } \\
\text { specific system setting }\end{array}$ \\
\hline Li and Benton ${ }^{40}$ & $\begin{array}{l}\text { Capacity management decision- } \\
\text { making (eg, expanding services, } \\
\text { partnering, investing in technology, } \\
\text { workforce management) in US } \\
\text { hospitals }\end{array}$ & $\begin{array}{l}\text { Questionnaire on hospital capacity management } \\
\text { decisions and } \\
\text { Practices, analysed using structural equation modelling }\end{array}$ & $\begin{array}{l}\text { To measure influence of hospital size, location, teaching } \\
\text { involvement, and service mix on hospital capacity resource } \\
\text { management decisions }\end{array}$ & $\begin{array}{l}\text { Covers technical decision-making in a } \\
\text { specific system setting }\end{array}$ \\
\hline Li and Benton ${ }^{41}$ & $\begin{array}{l}\text { Technology and nurse management } \\
\text { decisions in US Hospitals }\end{array}$ & $\begin{array}{l}\text { Questionnaire on technology and nurse management } \\
\text { decisions analysed using structural equation modelling }\end{array}$ & $\begin{array}{l}\text { To measure influence of hospital size and location on technology } \\
\text { and nurse management decisions }\end{array}$ & $\begin{array}{l}\text { Covers technical decision-making in a } \\
\text { specific system setting }\end{array}$ \\
\hline
\end{tabular}


Miller et al

K Local government commissioning

(ie, funding) decisions in the field of

public health

Review and synthesis of the

international literature on community

pharmacist decisions to adopt new

treatments

Review and synthesis of the

international literature on

disinvestment in healthcare

Roggenkamp et $\mathrm{al}^{44}$

US hospital decisions regarding

adoption of case management

State level health leaders in the US state of New York

terviews with local government commissioners

To identify the information that influences decisions on public health spending

To identify factors associated with community pharmacists' adoption decision-makin

To review the application of frameworks and tools for

disinvestment decision-making in health and social care

To investigate the adoption of case management by US hospitals at three-time periods:1994, 1997, and 2000

To determine the use of decision-making processes by state local health department leaders and barriers/facilitators to use of evidence-based decision-making

Review and synthesis of the international literature on macro/ meso level coverage decision-making in industrialised countries

Williams et al ${ }^{27}$ Health coverage decision-making in England and elsewhere

Mixed qualitative methods including individual and group interviews

Literature review

To analyse coverage decision-making processes

Literature review followed by documentary analysis and case studies (interviews and observation)

Community health centre decisions in the United States

\section{Qualitative interviews}

To investigates the role of economic evaluation in healthcare decision-making

To explore the role of consumer trustees in decision-makins under economic constraint
Covers allocative decision-making in a specific system setting

\section{Synthesises literature on allocative} decision although relatively little research identified

Covers allocative and technical decision across range of settings

Covers allocative and technical decisionmaking in a specific system settin

Covers decision-making in a specific system setting. Precise nature of decisions is somewhat unclear

\section{Covers allocative and technical}

decisions across range of settings. Not designed specifically to measure factors influencing decisions

Covers allocative decisions across range of settings

Covers allocative and technical decisionmaking, focussing on one specific contextual influencer

Abbreviations: MRI, magnetic resonance imaging; HMO, Health Maintenance Organisation. 
Table 2. Summary of Contextual Factors Cited by Literature Item

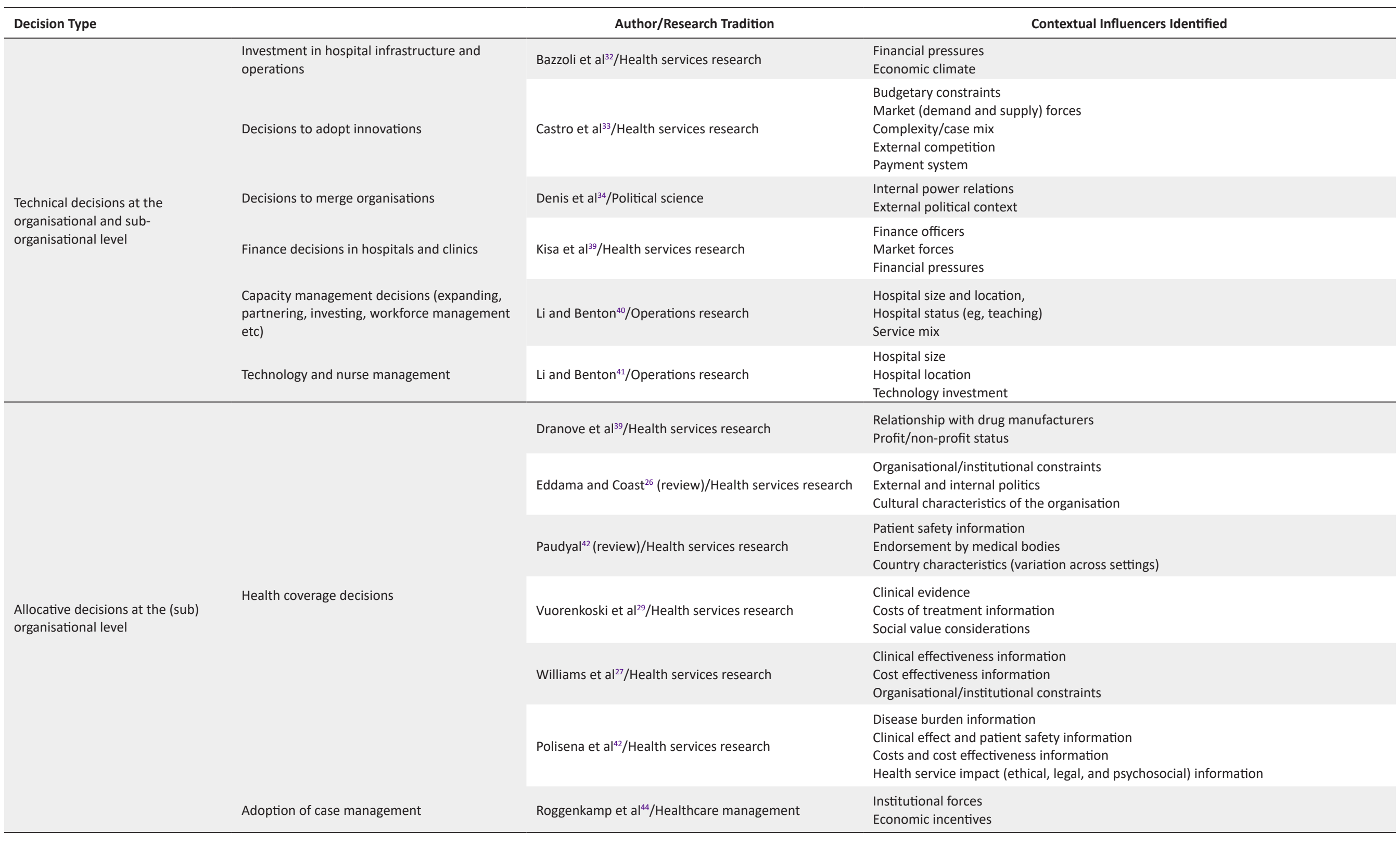




\begin{tabular}{|c|c|c|c|}
\hline \multirow{8}{*}{$\begin{array}{l}\text { Allocative decisions at the super- } \\
\text { organisational level }\end{array}$} & \multirow{4}{*}{ Health coverage decisions } & Eddama and Coast ${ }^{26}$ (review)/Health services research & Organisational/institutional forces \\
\hline & & Fischer ${ }^{36} /$ Health services research & $\begin{array}{l}\text { Clinical information } \\
\text { Economic information } \\
\text { Ethical considerations }\end{array}$ \\
\hline & & Vuorenkoski et al ${ }^{29}($ review)/Health services research & $\begin{array}{l}\text { Cost information } \\
\text { Past decisions } \\
\text { Severity of disease information } \\
\text { Patient demand } \\
\text { Clinical opinion } \\
\text { Pharmaceutical company behaviour }\end{array}$ \\
\hline & & Williams et $\mathrm{a}^{\mathrm{l}^{27}} /$ Health Services Research & $\begin{array}{l}\text { Clinical effectiveness information } \\
\text { Cost effectiveness information } \\
\text { Organisational/institutional constraints }\end{array}$ \\
\hline & Resource allocation in home care & $\begin{array}{l}\text { Fraser and Estabrooks }{ }^{28} / \text { Health services research } \\
\text { Fraser et } \mathrm{a}^{13} / \text { Health services research }\end{array}$ & $\begin{array}{l}\text { Client characteristics } \\
\text { Policy constraints } \\
\text { System constraints (work load and volume, staff turnover, organisational structure) } \\
\text { Resources }\end{array}$ \\
\hline & Investing in preventive/public programmes & Miller et al ${ }^{130} /$ Public management & $\begin{array}{l}\text { Political context } \\
\text { Interests }\end{array}$ \\
\hline & Disinvestment decisions & Polisena et $\mathrm{a}^{43} /$ Health services research & $\begin{array}{l}\text { Disease burden information } \\
\text { Clinical effect and patient safety information } \\
\text { Costs and cost effectiveness information } \\
\text { Health service impact (ethical, legal and psychosocial) }\end{array}$ \\
\hline & Health planning decisions & Hensher and Fulop ${ }^{38} /$ Health services research & $\begin{array}{l}\text { Needs assessment } \\
\text { Political bargaining between interest groups }\end{array}$ \\
\hline
\end{tabular}


include information accessed by decision-makers; interest groups within the organisation; organisational characteristics and governance structures.

\section{Sources of Information}

Levels of information and analytical resources are reported as important in shaping decisions of value, especially in relation to allocative decision-making. For example, technology coverage decisions have been found to be influenced by clinical, ethical and cost information. ${ }^{29,36,43}$ Absence of such information is also reported as important: for example high levels of uncertainty in the face of information deficits have been shown to reduce adherence to a instrumentalist decision-making model and to open up determinations to greater levels of judgement and intuition. ${ }^{27}$ Despite these findings, the relative importance of information (or its absence) can be over-stated and may be skewed by the prevalence of its pre-selection as a variable for analysis. ${ }^{26,27,30}$ Importantly, even in these studies information is invariably found to vie for primacy with other contextual drivers and influences. ${ }^{28,30,38}$

The role of information in technical decision-making at the organisational level is less well understood. Such evidence as exists suggests that decision-makers consult a range of information sources incorporating both explicit and tacit knowledge. ${ }^{30,45}$ These sources include professional journals, legal advisors, the media and the experiential information provided by other decision-makers, as well as advice from specialists. The relative importance attached to each source varies according to decision-maker characteristics such as age, occupation and education levels, as well the nature of the decisions themselves. For example highly technical areas of decision-making typically engender greater reliance on specialist information and advice. Professional roles appear to mediate the importance given to information: the literature contains instances of differences between decision-makers' emphasis on quality and cost considerations, with clinicians more likely to emphasize the former and budget holders/ finance professionals emphasizing the latter. ${ }^{27,33}$

The extent to which an organisation is able to identify and process new knowledge is likely to affect levels of rationality (ie, instrumentalism) in decision-making. However, as noted above, this knowledge is not confined to formal evidence. The literature provides support for the importance of tacit knowledge located in organisational memory and therefore of decision-making antecedents. However, workload levels are an important mediating variable in this regard and budgetary deficits have been cited as militating against an evidence based decision-making approach. ${ }^{45}$

\section{Interests}

The underlying premise of much of the discussion of interests is a concern with how power and self-interest are enacted by those not directly involved in the decision-making process. In general, internal actors and interests are reported as being highly influential in decision-making. ${ }^{38,34}$ However this influence can be uneven with, for example, 'experts' found to be more influential than lay or patient stakeholders in priority setting. ${ }^{29}$ Wright and Martin $^{46}$ conclude that 'consumer governors' in US community health centres are less influential than other stakeholders (eg, clinicians) even in relation to functions such as identification of community needs. Williams et $\mathrm{al}^{27}$ explore how interests are advanced through mobilisation of factors such as evidence and expertise, indicating the interrelationship between multiple factors within the inner context.

\section{Organisational and Institutional Characteristics}

Technical decision-making in particular is subject to the influence of organisational characteristics such as size, financial performance and service mix. In relation to size and service mix, Li and Benton ${ }^{40}$ conclude from a US survey that:

"Larger hospitals are more interested in expanding outpatient services, forging partnerships with physicians and managed care delivery systems, and seeking effective demand management decisions."

Service mix is also influential in technology adoption decision-making. ${ }^{40}$ For example teaching hospitals typically have more specialised and complex medical services, thereby increasing the resources and expertise available to them to support adoption decisions. The availability of slack resources for decision support and implementation, which are linked to organisational size, can affect decisions affecting costs and quality. ${ }^{28,47}$ However, the relationship between financial conditions and decision-making is complex and often unpredictable. Budgetary deficits have been found to militate against an evidence based decision-making approach. ${ }^{45}$ What's more, the uneven distribution of resources within and between organisations can lead to disparities of influence between interest groups. ${ }^{34}$ This again highlights the interrelationship between inner contextual factors such as resources, interests and organisational structure.

In some studies the term 'institution' is used to refer to characteristics of the broader (ie, supra-organisational) sector within which the decision-making function is located. Roggenkamp et $\mathrm{al}^{44}$ conclude that the foremost influences on decisions to adopt hospital case management are institutional rather than economic. By way of illustration they note that those most likely to benefit economically are not necessarily the most likely to adopt. Instead, they find inter-organisational factors such as the behaviour of competitors to be a more important predictor of decision-making. The literature includes multiple other references to institutional influence but with little commonality of meaning. For example, the term is employed as a synonym for organisations in some studies, and for market factors in others. Much of the detail of institutional influence is therefore discussed here under different headings.

\section{Governance and Leadership}

Extent of centralisation and specialisation has been linked to organisational performance, although less is known specifically about the impact of these on decision-making. In general there is a normative strain in the literature advocating decentralisation of decision-making and flatter management structures with increased autonomy at the front line. ${ }^{48}$ This links to the claim that autonomy and discretion/ 
responsibility are important in enabling rational decisionmaking. Respondents in Sosnowy and colleagues' ${ }^{35}$ study cite the importance of 'evidence-based' decision-making being promoted and supported by the leadership of the organisation. However more research is required into how these factors and others such as reporting relationships affect decisions of value. ${ }^{35}$

\section{Organisational Culture}

Although Eddama and Coast ${ }^{26}$ identify culture as a significant variable affecting the extent to which 'rational,' evidence-based decisions are made on investment in health and care, overall the review also notes that organizational culture and strategic orientation are not well understood in relation to decisionmaking. There has been extensive research into the values and norms that predominate in healthcare organisations $s^{49,50}$ and although there is a growing literature on the relationship between culture and performance there is little that focusses on decision-making either as an endpoint or an intervening variable. Indeed 'culture' has been described as the hardest organisational concept to define and this makes it difficult to measure its impact on decision-making. ${ }^{51}$ Clearly we might infer that culture shapes decision-making but there remains little by way of an evidence base on how this happens.

\section{Outer Context}

Influential factors deriving from the outer context include: geographical location; payment and reimbursement regimes; economic climate and; government and regulatory factors.

\section{Geography}

Geographical location has been found to be influential in relation to technical decision-making. For example decisions taken by health and care providers in rural areas are likely to be different to those taken in urban areas for reasons which include the skills requirements and capabilities of the workforce and the profile of patient populations. Li and Benton ${ }^{40,41}$ identify a greater emphasis on workforce development in rural areas where recruitment is often more constrained. Location therefore affects staffing decisions but can also be linked to factors such as case mix and complexity. This illustrates the interrelationship between inner and outer contextual factors, especially as traversed by professional networks which can be both within and outside of the decision-making organisation. ${ }^{29,42}$

\section{Interests}

A variety of groups external to the decision-making organisation can and often do exercise influence. These include members of the public, the media, legal bodies and professional representative bodies. The role that such parties play in allocative decision-making processes is better understood than it is in technical decision-making in health and care contexts. ${ }^{26}$ The media is frequently invoked as a counterforce to rational decision-making in its apparent promotion of unrealistic expectations and sensationalist causes, and/or in its role as a mouth piece for dissatisfied stakeholders.

\section{Economic Factors}

Economic factors in the form of resource pressures have consistently been found to influence technical decisionmaking at the organisation level. For example Bazzoli et $\mathrm{al}^{32}$ found that financial constraints contributed to decisions to reduce healthcare investment, and Roggenkamp et $\mathrm{al}^{44}$ found economic factors to be influential in decisions to adopt a case management approach in US hospitals. It is perhaps axiomatic to allocative decision-making that economic considerations are taken into account, although in practice these are often found to be secondary to other considerations. ${ }^{26,27}$

The influence of payment systems is illustrated in the literature through studies of, for example, the effects of reimbursement mechanisms on technology adoption. Castro et $\mathrm{al}^{33}$ found that a payment-per-case reimbursement system to be correlated with reduced rates of innovation adoption decisions, and elsewhere system characteristics have been found to influence case managers' resource allocation decisions. ${ }^{28}$ Similarly, Dranove et al. ${ }^{35}$ found that non-profit status made inclusion of new drugs on healthcare formularies more likely.

\section{Relationship to Government}

The role that government and/or regulatory bodies play in decision-making has been emphasized in a number of fields and this can affect organisations or individual decisionmakers operating within them. ${ }^{45,37}$ For example, hospital merger decisions have been found to be influenced by government pressure especially where public resources are the only funding source. ${ }^{34}$ Overall, much of the literature included within the review did not directly report on factors such as regulation, government contracts, service frameworks and standards.

\section{Intersecting Factors}

To mitigate factor selection bias in included literature, this table excludes studies where only a single influencing factor was selected for analysis (eg, Wright and Martin ${ }^{46}$ ). The literature clearly indicates that whilst factors can be disaggregated for analytical purposes they should not be treated as independent and many studies demonstrate how they intersect. For example, contextual factors are shown to affect levels of public engagement in decision-making, ${ }^{31}$ and hospital pharmacist drug adoption decisions are found to be influenced by a plethora of factors including: attributes of the medicine, professional opinion, resources and expertise, ethics and values, and patient opinion. ${ }^{42}$ Similarly, case manager resource allocation decisions are found to be shaped by a combination of system-related, home care programrelated, family-related, client-related factors, ${ }^{37}$ and evidence and interests are often intertwined in shaping decision outcomes. ${ }^{27}$ Dependent variables are themselves shown to act as factors influencing subsequent decisions. For example high levels of hospital investment in technology have been found to lead to high levels of investment in nurse training. ${ }^{41}$

\section{Discussion and Conclusions}

Enquiry into the relationship between quality and cost considerations in health and care decision-making is hampered 
by definitional confusion and there has been relatively little systematic exploration based on a shared conceptual understanding. Evidence synthesis therefore requires negotiation of the different terminologies that characterise the various literatures (as illustrated by the confusion noted earlier over the term 'institution'). The disciplinary variety encompassed in our included literature, and the attendant divergence in theoretical and methodological approaches, places serious caveats on the analytical claims that can be made. It is clear that study findings are heavily shaped by their design and by the contours of the research traditions from which they derive. In particular these limitations make it difficult to draw inferences about the relative importance of contextual factors in health and care decisions of value. ${ }^{52}$ It is also important to note that our sample of literature is heavily skewed towards high income countries, with only one middle income country study ${ }^{39}$ and none from lower income countries. However there are a number of observations that can reasonably be made with regard to the interplay of inner and outer context in shaping decisions of value in health and care. In this section of the paper we consider the conclusions that can be drawn based on the evidence presented thus far, and identify implications for theory, research and practice in relation to decisions of value.

Decision-makers do not operate in a vacuum and there are strong clinical, financial, and political imperatives that constrain choices. Within the inner context these are most pronounced in relation to technical rather than allocative decisions, and yet these decisions are less frequently investigated in the literature. Our analysis implies that technical organisational decision-making is more directly circumscribed by prevailing structures of incentives, penalties and rewards as well as the dominant organisational culture and relationships. By contrast allocative decision-makers are often granted partial separation or autonomy, and perhaps as a result are more often considered to exemplify an instrumentalist model of evidence-based and rational decision-making.

The review suggests that outer-contextual factors also play an important role in shaping both allocative and technical decisions of value. In other settings it has been found that degree of external control is inversely related to the degree of rationality adopted in decision-making ${ }^{18}$ and that environmental factors such as hostility and/or munificence in the political environment can be highly influential. ${ }^{19}$ In governmental health and care systems the sheer volume of external oversight and regulation mechanisms, not to mention legal opinion and precedent, can engender decision-making driven by compliance and risk aversion rather than outcomes. Hostile contexts can induce stress which in turn has been shown to influence decision-making. ${ }^{53,54}$ and similar claims have been made for external factors which increase levels of decision risk and uncertainty. ${ }^{55}$ In these situations, decisionmakers are more likely to fall back on intuition and experience than rational calculation. ${ }^{56}$ The implications of our analysis are therefore that excessive reform, regulation and scrutiny can induce response mode or risk-averse behaviour.

The nature of influence can be complex and multi-faceted, and the more distant the environmental factors the more difficult influence is to infer. There is a growing realisation that not only are the goals and values of much decision-making 'fuzzy' but the environment in which decisions are taken are also similarly fuzzy. ${ }^{57}$ The literature on complexity in health and care systems suggests that the relationship between decisionmaking and any single contextual factor is therefore unlikely to be linear. An ecological approach to understanding health and care systems would suggest that it is the multi-directional horizontal and vertical interplay between determinants and decision-makers that produce decisions and therefore the need to examine this interplay and its manifestations in specific settings.

Our review resonates with debates between normative rational choice theories of decision-making and descriptive organisational theories which emphasize context and environment. ${ }^{57}$ This is not the first time that decisionmaking has been shown to be complex and contingent on contextual factors. However, these empirical and theoretical insights are relatively under-explored in the health and care environment which remains heavily influenced by narrow, normative conceptions of decision-making which take insufficient account of the multiple and conflicting goals of governments and their agents at the meso level. ${ }^{58} \mathrm{~A}$ more responsive rationality, in which multiplicity is negotiated iteratively according to changes in context, is likely to be more practically useful. ${ }^{59}$

It is clear from the review that the variety and complexity that characterises decisions of value in health and care confounds simple prescriptions for improvements to practice especially considering mediating factors such as the nature of the decision (scale, levels of certainty, expected impact). Allocation of resources to, for example, service expansion and contraction, staff training, recruitment, public engagement and so on, will only be effective where it is informed by a detailed understanding of local context. Calculation of these factors as well as the expected controversy and impact of decisions could help determine the amount of time and information required to discharge decision-making as well as the extent to which prior buy-in will need to be secured from affected parties.

In relation to information, levels of resource mobilised should be roughly commensurate with the scale and likely impact of decisions. Rational decision-making is enhanced where investment in option appraisal, decision modelling, and other forms of information and analysis is greatest. However this should be offset against opportunity cost of investing resources in this area. A good example of this is formal cost-effectiveness analysis which has been applied with some success to allocative decision-making at a macro level but which remains something of an expensive luxury at sub-tiers. ${ }^{60}$ The implications of these insights for decisionmaking in health and care are that important factors to consider include whether sufficient investment is made in the resources required to generate and interpret information relevant to decisions, and whether both explicit and tacit knowledge channels are facilitated.

Finally, the review has underlined the influence of interest 
groups. Where decisions affecting costs and quality are of significant scale and scope there is a strong normative case for involving patients and citizens. The logic of involving the public relates to their voice in relation to how public resources are spent and therefore has particular salience in relation to allocative decisions - for example priority setting, commissioning and disinvestment. The logic of involving patients derives primarily from their status as the intended beneficiaries of health and care services and their expertise in relation to understanding quality.

Just as it has been argued that alignment between organisational operating mechanisms and decision mechanisms, facilitates better organisational decision-making, ${ }^{61}$ our review underlines the importance of alignment with wider context. This suggests the importance of investigating how the factors identified interact and cohere in local settings. To this end, there is a requirement for development of a conceptual schema combining influential factors related specifically to decisionmaking. We hope that this paper sensitises us to key concepts and terms to inform such work, and that in time it will help to facilitate comprehensive, multivariate factor analysis across a range of decisions.

\section{Acknowledgements}

The authors acknowledge the NHS Confederation, London, UK and the Academy of Medical Royal Colleges for funding this literature review as part of a wider investigation into 'decisions of value in healthcare.'

\section{Ethical issues}

Not applicable.

\section{Competing interests}

Authors declare that they have no competing interests.

\section{Authors' contributions}

IW led the process of search strategy design and contributed to analysis. He led write-up of the manuscript. HB carried out searches and contributed to analysis and write-up of the manuscript. $\mathrm{PH}$ contributed to search strategy design, analysis, and write-up of the manuscript.

\section{Authors' affiliations}

${ }^{1}$ Health Services Management Centre, University of Birmingham, Birmingham, UK. ${ }^{2} \mathrm{NHS}$ Confederation, London, UK.

\section{References}

1. Berwick DM, Nolan TW, Whittington J. The triple aim: care, health, and cost. Health Aff (Millwood). 2008;27(3):759-769. doi:10.1377/ hlthaff.27.3.759

2. Pettigrew AM. The awakening giant: continuity and change in Imperial Chemical Industries. Chichester: Wiley Blackwell; 1985.

3. Academy of Medical Royal Colleges/NHS Confederation. Decisions of Value: summary of findings. http://www.nhsconfed. org/-/media/Confederation/Files/Publications/Documents/ Decisions-of-Value_Final-report-and-findings.pdf. Accessed November 17, 2015.

4. Beauvais $B$, Wells $R$. Does money really matter? A review of the literature on the relationships between healthcare organization finances and quality. Hosp Top. 2006;84(2):20-28. doi:10.3200/ htps.84.2.20-29

5. Williams I. Organizational readiness for innovation in health care: some lessons from the recent literature. Health Serv Manage Res. 2011;24(4):213-218. doi:10.1258/hsmr.2011.011014

6. Brown P, Alaszewski A, Pilgrim D, Calnan M. The quality of interaction between managers and clinicians: a question of trust.
Public Money Management. 2011;31(1):43-50. doi:10.1080/0954 0962.2011 .545546

7. Brehmer B. Dynamic decision making: human control of complex systems. Acta Psychol (Amst). 1992;81(3):211-241.

8. Robert G, Harlock J, Williams I. Disentangling rhetoric and reality: an international Delphi study of factors and processes that facilitate the successful implementation of decisions to decommission healthcare services. Implement Sci. 2014;9:123. doi:10.1186/ s13012-014-0123-y

9. Lin V, Gibson B. Evidence-Based Health Policy. Melbourne, VIC: Oxford University Press; 2003.

10. Simon HA. Information-processing theory of human problem solving. Handbook Learning Cognitive Processes. 1978;5:271295.

11. McCaughey D, Bruning NS. Rationality versus reality: the challenges of evidence-based decision making for health policy makers. Implement Sci. 2010;5:39. doi:10.1186/1748-5908-5-39

12. Davis JH. Group decision and social interaction: a theory of social decision schemes. Psychol Rev. 1973;80(2):97-125. doi:10.1037/ h0033951

13. Kahneman D, Tversky A. Prospect theory: an analysis of decision under risk. Econometrica. 1979;47(2):263-291. doi:10.2307/1914185

14. Reyna VF, Brainerd CJ. Fuzzy-trace theory and framing effects in choice: Gist extraction, truncation, and conversion. J Behav Decis Mak. 1991;4(4):249-262. doi:10.1002/bdm.3960040403

15. Dobrow MJ, Goel V, Upshur RE. Evidence-based health policy: context and utilisation. Soc Sci Med. 2004;58(1):207-217.

16. Parayitam S, Phelps LD, Olsen BJ. Strategic decision-making in the healthcare industry: the effects of physician executives on decision outcomes. Management Research News. 2007;30(4):283-301. doi:10.1108/01409170710736329

17. Shayo EH, Norheim OF, Mboera LE, et al. Challenges to fair decision-making processes in the context of health care services: a qualitative assessment from Tanzania. Int $J$ Equity Health. 2012;11:30. doi:10.1186/1475-9276-11-30

18. Goll I, Rasheed AA. The relationships between top management demographic characteristics, rational decision making, environmental munificence, and firm performance. Organization Studies. 2005;26(7):999-1023. doi:10.1177/0170840605053538

19. Shepherd NG, Rudd JM. The influence of context on the strategic decision-making process: a review of the literature. Int J Manag Rev. 2014;16(3):340-364. doi:10.1111/ijmr.12023

20. Suchman MC. Managing legitimacy: strategic and institutional approaches. Acad Manage Rev. 1995;20(3):571-610. doi:10.5465/ AMR.1995.9508080331

21. Pye A, Pettigrew A. Studying board context, process and dynamics: some challenges for the future. Br J Manag. 2005;16(s1):S27-S38. doi:10.1111/j.1467-8551.2005.00445.x

22. Bate SP, Mendel P, Robert G. Organising for quality: the improvement journeys of leading hospitals in Europe and the United States. Oxford: Radcliffe Publishing; 2008.

23. Squires JE, Graham ID, Hutchinson AM, et al. Identifying the domains of context important to implementation science: a study protocol. Implement Sci. 2015;10:135. doi:10.1186/s13012-0150325-y

24. Khan K, Terriet G, Sowden A, Kleijnen J. Undertaking systematic reviews of research on effectiveness: CRD's guidance for carrying out or commissioning reviews. UK NHS Centre Reviews Dissemination; 2008.

25. Mays N, Pope C, Popay J. Systematically reviewing qualitative and quantitative evidence to inform management and policymaking in the health field. J Health Serv Res Policy. 2005;10 Suppl 1:6-20. doi:10.1258/1355819054308576

26. Eddama O, Coast J. A systematic review of the use of economic evaluation in local decision-making. Health Policy. 2008;86(23):129-141. doi:10.1016/j.healthpol.2007.11.010

27. Williams I, Mclver S, Moore D, Bryan S. The use of economic evaluations in NHS decision-making: a review and empirical investigation. Health Technol Assess. 2008;12(7):iii.

28. Fraser KD, Estabrooks C. What factors influence case 
managers' resource allocation decisions? A systematic review of the literature. Med Decis Making. 2008;28(3):394-410. doi: $10.1177 / 0272989 \times 07312709$

29. Vuorenkoski L, Toiviainen H, Hemminki E. Decision-making in priority setting for medicines--a review of empirical studies. Health Policy. 2008;86(1):1-9. doi:10.1016/j.healthpol.2007.09.007

30. Miller R, Williams I, Allen K, Glasby J. Evidence, insight, or intuition? Investment decisions in the commissioning of prevention services for older people. J Care Serv Manag. 2013;7(4):119-127. doi:10.1179/1750168714Y.0000000027

31. Abelson J. Understanding the role of contextual influences on local health-care decision making: case study results from Ontario, Canada. Soc Sci Med. 2001;53(6):777-793.

32. Bazzoli GJ, Clement JP, Lindrooth RC, et al. Hospital financial condition and operational decisions related to the quality of hospital care. Med Care Res Rev. 2007;64(2):148-168. doi:10.1177/1077558706298289

33. Finocchiaro Castro M, Guccio C, Pignataro G, Rizzo I. The effects of reimbursement mechanisms on medical technology diffusion in the hospital sector in the Italian NHS. Health Policy. 2014;115(23):215-229. doi:10.1016/j.healthpol.2013.12.004

34. Denis JL, Champagne F, Contandriopoulos AP, Cazale L. Determinants of a merger in a publicly-funded health system: a political-economy perspective. Int $\mathrm{J}$ Health Plann Manage. 1992;7(2):79-101.

35. Dranove D, Hughes EF, Shanley M. Determinants of HMO formulary adoption decisions. Health Serv Res. 2003;38(1 Pt 1):169-190

36. Fischer KE. A systematic review of coverage decision-making on health technologies-evidence from the real world. Health Policy. 2012;107(2-3):218-230. doi:10.1016/j.healthpol.2012.07.005

37. Fraser KD, Estabrooks C, Allen M, Strang V. Factors that influence case managers' resource allocation decisions in pediatric home care: an ethnographic study. Int J Nurs Stud. 2009;46(3):337-349. doi:10.1016/j.ijnurstu.2008.10.001

38. Hensher $M$, Fulop $N$. The influence of health needs assessment on health care decision-making in London health authorities. J Health Serv Res Policy. 1999;4(2):90-95. doi:10.1177/135581969900400206

39. Kisa A, Kavuncubasi S, Ersoy K. The influence of financial officers on the decision-making process in health facilities: a study in Ankara. Health Care Manag (Frederick). 2006;25(1):37-42.

40. Li L, Benton WC. Hospital capacity management decisions: Emphasis on cost control and quality enhancement. Eur J Oper Res. 2003;146(3):596-614. doi:10.1016/S0377-2217(02)00225-4

41. Li L, Benton WC. Hospital technology and nurse staffing management decisions. Journal of Operations Management 2006;24(5):676-691.

42. Paudyal V, Hansford D, Cunningham S, Stewart D. Community pharmacists' adoption of medicines reclassified from prescriptiononly status: a systematic review of factors associated with decision making. Pharmacoepidemiol Drug Saf. 2012;21(4):396406. doi: $10.1002 /$ pds.3219

43. Polisena J, Clifford T, Elshaug AG, Mitton C, Russell E, Skidmore B. Case studies that illustrate disinvestment and resource allocation decision-making processes in health care: a systematic review. Int J Technol Assess Health Care. 2013:29(2):174-184. doi:10.1017/s0266462313000068

44. Roggenkamp SD, White KR, Bazzoli GJ. Adoption of hospital case management: economic and institutional influences. Soc Sci Med.
2005:60(11):2489-2500. doi:10.1016/j.socscimed.2004.11.010

45. Sosnowy CD, Weiss LJ, Maylahn CM, Pirani SJ, Katagiri NJ. Factors affecting evidence-based decision making in local health departments. Am J Prev Med. 2013;45(6):763-768. doi:10.1016/j. amepre.2013.08.004

46. Wright B, Martin GP. Mission, margin, and the role of consumer governance in decision-making at community health centers. $J$ Health Care Poor Underserved. 2014;25(2):930-947. doi:10.1353/ hpu.2014.0107

47. Berta W, Laporte A, Kachan N. Unpacking the relationship between operational efficiency and quality of care in Ontario longterm care homes. Can J Aging. 2010;29(4):543-556. doi:10.1017/ s0714980810000553

48. Foot C, Sonola L, Maybin, J, Naylor C. Service-line management. Can it improve quality and efficiency? London: Kings Fund; 2012.

49. Davies HT, Mannion R, Jacobs R, Powell AE, Marshall MN. Exploring the relationship between senior management team culture and hospital performance. Med Care Res Rev. 2007;64(1):46-65. doi:10.1177/1077558706296240

50. Stock GN, McFadden KL, Gowen CR. Organizational culture critical success factors, and the reduction of hospital errors. Int $J$ Prod Econ. 2007;106(2):368-392.

51. 51 Konteh FH, Mannion R, Davies HT. Clinical governance views on culture and quality improvement. Clinical Governance: An International Journal. 2008;13(3):200-207. doi:10.1108/14777270810892610

52. Papadakis VM, Lioukas S, Chambers D. Strategic decisionmaking processes: the role of management and context. Strategic Management Journal. 1998;19(2):115-147. doi:10.1002/ (SICI)1097-0266(199802)19:2<115::AID-SMJ941>3.0.CO;2-5

53. Keinan G, Friedland N, Ben-Porath Y. Decision making under stress: Scanning of alternatives under physical threat. Acta Psychol. 1987;64(30:219-228. doi:10.1016/0001-6918(87)90008-

54. Starcke K, Wolf OT, Markowitsch HJ, Brand M. Anticipatory stress influences decision making under explicit risk conditions. Behav Neurosci. 2008:122(6):1352-1360. doi:10.1037/a0013281

55. Zinn JO. Heading into the unknown: Everyday strategies for managing risk and uncertainty. Health Risk Society. 2008;10(5):439450. doi:10.1080/13698570802380891

56. Pfister HR, Bohm,G. The multiplicity of emotions: a framework of emotional functions in decision making. Judgm Decis Mak. 2008;3(1):5-17

57. Bellman RE, Zadeh LA. Decision-making in a fuzzy environment. Manage Sci. 1970;17(4):B-141-B-164. doi:10.1287/mnsc.17.4.B141

58. Zey M. Criticisms of rational choice models. In: Zey M, ed. Decision-making: Alternatives to rational choice models. Newbury Park, CA: Sage Publications; 1992: 10-31.

59. Nalbandian J, Klingner DE. Integrating context and decision strategy: a contingency theory approach to public personnel administration. Adm Soc. 1980;12(2):178-202. doi:10.1177/009539978001200204

60. Mousavi S, Garrison J. Toward a transactional theory of decision making: creative rationality as functional coordination in context. Journal Economic Methodology. 2003;10(2):131-156. doi:10.1080/1350178032000071039

61. Williams I. Institutions and health care rationing: the example of health care coverage in the English National Health Service. Policy Polit. 2013;41(2):223-239. doi:10.1332/030557312X655477 